\title{
Retinal Detachment After Endophthalmitis: Risk Factors and Outcomes
}

This article was published in the following Dove Press journal:

Clinical Ophthalmology

\author{
Tiantian Wang ${ }^{1,2}$ \\ Omar Moinuddin (D) \\ Rebhi Abuzaitoun' \\ Min Hwang $\mathbb{D}^{1}$ \\ Cagri Besirli \\ Thomas J Wubben (iD) \\ David N Zacks' \\ 'Department of Ophthalmology and \\ Visual Sciences, University of Michigan W. \\ K. Kellogg Eye Center, Ann Arbor, MI, \\ USA; ${ }^{2}$ Department of Ophthalmology, \\ Xiangya Hospital, Central South \\ University, Changsha, Hunan, People's \\ Republic of China
}

Purpose: To analyze the risk factors, clinical course, and visual and anatomic outcomes of retinal detachment (RD) after endophthalmitis.

Patients and Methods: This retrospective study included 108 patients diagnosed with endophthalmitis between August 2014 and May 2019 at a single tertiary referral center. Sixteen patients developed RD after endophthalmitis. Retrospective analysis was performed to compare the cohort of endophthalmitis alone versus the cohort that developed RD after endophthalmitis, with analysis of potential risk factors for RD after endophthalmitis and treatment outcomes.

Results: The incidence of RD after endophthalmitis was $14.8 \%(\mathrm{~N}=16 / 108)$. The median time to develop RD after endophthalmitis was 27 days (range: 1-581 days, IQR: 25.3). Thirteen $(81.3 \%)$ cases of RD occurred less than 2 months after the diagnosis of endophthalmitis. The incidence of aphakia $(p=0.023)$ and posterior synechia (PS) $(p=0.014)$ were significantly higher in the RD group. The mean initial and final visual acuity (VA) of the endophthalmitis alone group was $1.9 \pm 0.8 \log$ MAR and $1.2 \pm 1.0 \log \mathrm{MAR}(\mathrm{p}<0.0001)$, respectively, and $1.9 \pm 0.9 \operatorname{logMAR}$ and $1.3 \pm 1.2 \log \mathrm{MAR}(\mathrm{p}=0.07)$ in the RD group, respectively. Enucleation or evisceration occurred in $31.3 \%$ of cases with RD after endophthalmitis. The rate of final retinal re-apposition for the RD cohort was $56.3 \%$.

Conclusion: The anatomic and functional outcomes for RD after endophthalmitis remain poor, with significant risk for permanent vision loss. Aphakia and posterior synechiae were seen more often in cases with RD after endophthalmitis.

Keywords: pars plana vitrectomy, intraocular inflammation, aphakia, posterior synechiae, vision loss

\section{Introduction}

Infectious endophthalmitis is an emergent ophthalmic condition characterized by purulent inflammation of the intraocular structures caused by endogenous or exogenous pathogens, and may lead to permanent and irreversible loss of vision. ${ }^{1,2}$ Intravitreal antibiotics and pars plana vitrectomy (PPV) are the mainstay of treatment, with systemic antibiotic treatment often added primarily for endogenous infections. Along with antibiotics, a vitreous and/or aqueous biopsy (with or without vitrectomy) with microbiologic testing is routinely performed to determine infectious etiology. ${ }^{3,4}$ A severe complication of endophthalmitis is the subsequent development of retinal detachment (RD), which has been reported in up to $25 \%$ of cases of endophthalmitis. $^{5-9}$

While several previous study groups have explored potential precipitating factors and clinical course, as it stands, there does not exist an evidence-based
Correspondence: David N Zacks

University of Michigan, Kellogg Eye

Center, 1000 Wall St., Ann Arbor, MI, 48105

$\mathrm{Tel}+\mid$ 734-936-087|

Email davzacks@umich.edu
Clinical Ophthalmology 2021:15 1529-1537 in $\mathbf{P}$ 
consensus on the risk factors that contribute to the development of RD after endophthalmitis. Likewise, there is limited literature correlating examination findings at the time of diagnosis of endophthalmitis and infectious etiologies with RD incidence and prognosis. A few studies have suggested that the virulence of organisms, posterior capsular rupture after cataract surgery, and vitreous prolapse are risk factors for the development of RD after endophthalmitis. ${ }^{5,6}$ Diabetes and retinal vasculitis have also been reported to increase the likelihood of $\mathrm{RD}$ after exogenous endophthalmitis. ${ }^{6,8}$ Though seldom mentioned, RD may occur as a result of membranous scar tissue formation even after the inflammation has subsided. ${ }^{10}$ Unlike the majority of patients with primary, noncomplex rhegmatogenous retinal detachment, patients who develop RD after endophthalmitis generally have a poor visual prognosis, with up to two-thirds of all patients achieving a best corrected visual acuity (BCVA) of 20/400 or less even after surgical repair. ${ }^{11}$

The purpose of this study was to assess the incidence, potential risk factors, and underlying mechanisms related to the occurrence and outcomes of RD after endophthalmitis in a manner that is not restricted to the etiology of endophthalmitis, severity of initial vision, or limited selection of operative procedure as in previous literature. $5,6,8,12$ Specifically, we discuss the clinical course, virulence of pathogens, and visual and anatomic outcomes.

\section{Patients and Methods}

This is a retrospective, non-consecutive case series of patients seen at the University of Michigan/W.K. Kellogg Eye Center between August 2014 and May 2019. The Institutional Review Board of the University of Michigan (Ann Arbor, MI, USA) approved the research, and it conformed to the tenets of Health Insurance Portability and Accountability Act (HIPAA) and the Declaration of Helsinki. Patients who were included in this study were identified based on a review of International Classification of Diseases (ICD) diagnostic codes (see Supplemental Table). Patients with either endogenous or exogenous endophthalmitis alone or RD after endophthalmitis were included. As the study focused on the time point of RD after endophthalmitis, cases with RD before or concurrent with endophthalmitis were excluded. Only individuals diagnosed with retinal detachment after previously being diagnosed with endophthalmitis, and then undergoing vitreoretinal surgical repair with at least 3 months of documented follow-up were included in this study. The minimum follow-up of 3 months was set in order to best ascertain anatomic outcomes postoperatively.

In each case, a diagnosis of endophthalmitis was made based on clinical manifestations, such as eye pain, vitritis, loss of vision, hypopyon, red eye, periocular swelling, as well as review of each individual patient's history of presenting illness. Data collected included demographic information, clinical and microbiological characteristics, and preoperative, perioperative, and postoperative information located in the electronic medical record (EMR). For culture-positive cases, microorganisms were categorized as less virulent (coagulase negative Staphylococcus (CoNS) and fungus) or more virulent (Staphylococcus aureus, gram-negative bacteria, Streptococcus species, and Bacillus species). ${ }^{6,11,13}$ Endophthalmitis cases were classified as endogenous or exogenous based on the presenting history, and the virulence was based on the results of microbiologic cultures. Endogenous endophthalmitis was defined as endophthalmitis in the setting of an existing systemic or localized organ infection that has reasonable potential to hematologically spread to the ocular tissues. Exogenous endophthalmitis was defined if occurred subsequent to surgery (postoperative), intravitreal injection, perforating or penetrating trauma, diagnosis of corneal ulcer within the past 6 months or associated with a filtering bleb. Postoperative endophthalmitis was divided into two sub-types. Late-onset postoperative exogenous endophthalmitis was defined as those cases that presented more than 42 days (6 weeks) after surgery. Acute postoperative exogenous endophthalmitis was defined as those cases that presented less than 42 days after surgery. ${ }^{9}$

The anatomic outcomes in this study included final status of retinal re-apposition and enucleation or evisceration. Visual acuity (VA) was based on the Snellen visual acuity, which was converted to $\log$ MAR for statistical analysis. Pinhole Snellen VA was used in place of bestcorrected visual acuity due to the retrospective nature of this study. CF, hand motion (HM), light perception (LP) and no light perception (NLP) vision were converted to logMAR as follows: CF 1.9, HM: 2.3, LP: 2.7, NLP: $3.0 .^{14,15}$

There were 127 patients identified. Ten patients with $\mathrm{RD}$ before the diagnosis of endophthalmitis, five patients with concurrent $\mathrm{RD}$ and endophthalmitis, two patients with RD in the fellow eye, and two patients with followup time less than 3 months after surgery were excluded. This resulted in 108 endophthalmitis patients being included in this study, 16 of which developed RD after 
endophthalmitis. Patients who underwent enucleation or evisceration $(\mathrm{N}=13)$ were not included in the analysis of the final VA, as there was no record of VA on the last office visit. As per the Institutional Review Board (IRB) at The University of Michigan, informed patient consent was not required to review patient medical data for research. Moreover, given that all patient information remained deidentified throughout data analysis and the drafting of this manuscript, informed patient consent was not deemed to be necessary by the IRB.

GraphPad Prism 8.0.2 (San Diego, CA) software was utilized for statistical analyses. The Shapiro-Wilk test of normality was performed to select parametric/nonparametric test. Fisher's exact test and Student $t$-test (paired or unpaired) were separately used to measure the difference between groups for categorical and continuous variables, with $\mathrm{P}<0.05$ necessary for significance.

\section{Results}

\section{All Cases of Endophthalmitis $(n=108)$}

The characteristics of all patients with endophthalmitis are summarized in Table 1. Overall, 108 patients with endophthalmitis were identified, with $51 \%$ being male $(\mathrm{n}=55)$. The mean age was $67 \pm 17$ years (range: 1-94 years). The mean follow-up time was $23.5 \pm 21.7$ months (range: 2 days to 76 months). The etiology of endophthalmitis was exogenous in $93(86.1 \%)$ cases and endogenous in 15 (13.9\%) cases. Endophthalmitis was postoperative in 42 (38.9\%) cases, associated with intravitreal injection in 21 (19.4\%) cases, due to corneal ulcer in 17 (14.8\%) cases, secondary to penetrating or perforating globe injury 6 $(5.6 \%)$ cases, and bleb-associated in $6(5.6 \%)$ cases. For patients in the postoperative cohort, the majority was acute $(\mathrm{N}=27,64.3 \%)$. The mean VA at the time of diagnosis of endophthalmitis was 2.0 \pm 0.8 logMAR (range: 0.2-3 logMAR; Snellen equivalent, 20/1910 [range, 20/30-NLP]) with the majority of patients presenting with $20 / 400$ or worse vision $(\mathrm{N}=85,78.7 \%)$. As to lens status at the time of diagnosis of endophthalmitis, 63 patients were pseudophakic, 40 were phakic, and 5 were aphakic. Sixty-five (60.2\%) patients had primary cataract surgery, after which 3 were aphakic. The remaining two patients were aphakic due to trauma or pars plana lensectomy. Microbial cultures were positive in $55.6 \%$ of the patients $(60 / 108)$ and CoNS was the most commonly observed microorganism $(\mathrm{N}=22$, 36.7\%). All patients received intravitreal injection of antibiotics (IVAB), with the combination of vancomycin $1 \mathrm{mg} /$
Table I Characteristics of All Patients with Endophthalmitis $(n=108)$

\begin{tabular}{|c|c|c|c|}
\hline \multicolumn{2}{|c|}{ Characteristics } & \multicolumn{2}{|l|}{ Number (\%) } \\
\hline \multicolumn{2}{|c|}{$\begin{array}{l}\text { Mean follow-up time } \pm \text { SD } \\
\text { (months) }\end{array}$} & \multicolumn{2}{|l|}{$23.5 \pm 21.7$} \\
\hline \multicolumn{2}{|c|}{ Mean age $\pm S D$ (years) } & \multicolumn{2}{|l|}{$67 \pm 17$} \\
\hline \multirow{2}{*}{\multicolumn{2}{|c|}{ Sex }} & Male & $55(50.9)$ \\
\hline & & Female & $53(49.1)$ \\
\hline \multirow[t]{6}{*}{ Etiology } & Exogenous & Postoperative & $42(38.9)$ \\
\hline & & Post intravitreal injection & $21(19.4)$ \\
\hline & & Corneal ulcer related & $16(14.8)$ \\
\hline & & Traumatic & $6(5.6)$ \\
\hline & & Filtering bleb associated & $6(5.6)$ \\
\hline & Endogenous & & $15(13.9)$ \\
\hline \multirow{2}{*}{\multicolumn{2}{|c|}{ Initial VA }} & $\geq 20 / 400$ & $23(2 \mid .3)$ \\
\hline & & $<20 / 400$ & $85(78.7)$ \\
\hline \multirow{3}{*}{\multicolumn{2}{|c|}{ Lens status }} & Pseudophakic & $63(58.3)$ \\
\hline & & Phakic & $40(37.0)$ \\
\hline & & Aphakic & $5(4.6)$ \\
\hline \multirow{10}{*}{\multicolumn{2}{|c|}{ Ocular culture }} & Positive & $60(55.6)$ \\
\hline & & Organisms & \\
\hline & & CoNS & $22(36.7)$ \\
\hline & & Streptococcus species & $19(31.7)$ \\
\hline & & MRSA & $6(10)$ \\
\hline & & MSSA & $3(5)$ \\
\hline & & Gram-negative bacteria & $5(8.3)$ \\
\hline & & Candida albicans & $2(3.3)$ \\
\hline & & Enterococcus faecalis & $2(3.3)$ \\
\hline & & Fusarium & $\mathrm{I}(\mathrm{I} .7)$ \\
\hline \multirow{2}{*}{\multicolumn{2}{|c|}{ Treatment }} & IVAB alone & $82(75.9)$ \\
\hline & & $P P V+I V A B$ & $26(24.1)$ \\
\hline \multirow{2}{*}{\multicolumn{2}{|c|}{ Final VA }} & $\geq 20 / 400$ & $55(57.9)$ \\
\hline & & $<20 / 400$ & $40(42.1)$ \\
\hline
\end{tabular}

Abbreviations: VA, visual acuity; CoNS, coagulase-negative staphylococci; MRSA, methicillin-resistant Staphylococcus aureus; MSSA, methicillin-susceptible Staphylococcus aureus; IVAB, intravitreal antibiotics; PPV, pars plana vitrectomy.

$0.1 \mathrm{~mL}$ and ceftazidime $2.25 \mathrm{mg} / 0.1 \mathrm{~mL}$ being the most common treatment regimen $(\mathrm{N}=89,82.4 \%)$. Twenty-six patients underwent pars plana vitrectomy (PPV) in addition to intravitreal antibiotic treatment. The mean final VA, excluding the 13 cases who had enucleation/evisceration, was $1.2 \pm 1.0 \log$ MAR (range: -0.1 to $3 \log$ MAR; Snellen equivalent, 20/332 [range, 20/15-NLP], N=95). Posttreatment vision was worse than $20 / 400$ in $40(42.1 \%)$ patients. The mean final VA of patients who underwent both PPV and IVAB was $1.20 \pm 1.10 \log$ MAR (range, 0 to $3 \operatorname{logMAR}$; Snellen equivalent, 20/317 [range, 20/20 to 
NLP], N=21), similar to $1.22 \pm 1.00 \log$ MAR (range: -0.1 to $3 \log$ MAR; Snellen equivalent, 20/332 [range, 20/15-NLP], $\mathrm{N}=74$ ) for patients who received IVAB alone $(\mathrm{p}=0.94)$.

\section{RD After Endophthalmitis $(n=16)$}

Sixteen patients developed RD subsequent to endophthalmitis diagnosis (Table 2). The mean age of this cohort was 60 \pm 18 years (range: $12-87$ ), and 9 (56.3\%) patients were male. The incidence of RD after endophthalmitis in this study was $14.8 \%(\mathrm{~N}=16 / 108)$. The frequency of $\mathrm{RD}$ was $11.5 \%(\mathrm{~N}=3$ /
26) in patients who had PPV along with IVAB, as compared to $15.9 \%(\mathrm{~N}=13 / 82)$ for patients with IVAB alone. Five (7.9\%) patients with pseudophakia developed RD. Among patients who had cataract surgery before endophthalmitis, six (9.2\%) patients developed RD. The mean follow-up time for all 16 cases was $22.7 \pm 19.9$ (range: 1-63) months.

Three quarters of the patients with $\mathrm{RD}$ had exogenous endophthalmitis ( $\mathrm{N}=12 / 16)$. Among them, 5 (41.7\%) had postoperative endophthalmitis, including two cases (No. 12, 16) after keratoprosthesis (KPRO), and three cases

Table 2 Presenting Characteristics of Patients Who Developed RD Subsequent to Endophthalmitis

\begin{tabular}{|c|c|c|c|c|c|c|c|c|}
\hline $\begin{array}{l}\text { Case } \\
\text { No. }\end{array}$ & Age & Sex & Etiology & $\begin{array}{l}\text { Lens } \\
\text { Status }\end{array}$ & $\begin{array}{l}\text { Ocular } \\
\text { Culture }\end{array}$ & Organism & $\begin{array}{l}\text { Treatment [Times } \\
\text { Provided/Interval (Days)] }\end{array}$ & $\begin{array}{l}\text { Initial } \\
\text { VA* }\end{array}$ \\
\hline 1 & 71 & $M$ & Trauma & Phakia & Negative & l & IVAB (I) & $\mathrm{CF}$ \\
\hline 2 & 43 & $\mathrm{~F}$ & $\begin{array}{l}\text { Endogenous (lung pleura } \\
\text { abscess) }\end{array}$ & Phakia & Negative & l & $\operatorname{IVAB}(3 / 6)$ & $\mathrm{CF}$ \\
\hline 3 & 57 & $M$ & Endogenous (meningitis) & Phakia & Positive & CoNs & $\operatorname{IVAB}(2 / 10)$ & LP \\
\hline 4 & 59 & $M$ & $\begin{array}{l}\text { Postoperative (44 days } \\
\text { after } K P E / I O L)\end{array}$ & PCIOL & Negative & l & $\operatorname{IVAB}(\mathrm{I})$ & $20 / 150$ \\
\hline 5 & 65 & $\mathrm{~F}$ & $\begin{array}{l}\text { Intravitreal injection } \\
\text { (bevacizumab) }\end{array}$ & Phakia & Positive & CoNS & $\operatorname{IVAB}(I)$ & HM \\
\hline 6 & 38 & $M$ & Corneal ulcer & Aphakia & Negative & l & $\operatorname{IVAB}(I)$ & LP \\
\hline 7 & 64 & $\mathrm{~F}$ & Trauma & Aphakia & Positive & MRSA & IVAB (I) & HM \\
\hline 8 & 60 & $M$ & $\begin{array}{l}\text { Postoperative ( } 4 \text { days after } \\
\text { KPE/IOL) }\end{array}$ & PCIOL & Positive & CoNS & $\operatorname{IVAB}(2 / 2)$ & $20 / 250$ \\
\hline 9 & 70 & $M$ & $\begin{array}{l}\text { Endogenous (urinary tract } \\
\text { infection) }\end{array}$ & Phakia & Negative & l & $\operatorname{IVAB}(2 / I)$ & NLP \\
\hline 10 & 52 & $\mathrm{~F}$ & Corneal ulcer & Phakia & Positive & $\begin{array}{l}\text { Viridans Group } \\
\text { Streptococcus }\end{array}$ & $\operatorname{IVAB}(2 / 2)$ & NLP \\
\hline II & 78 & $\mathrm{~F}$ & $\begin{array}{l}\text { Postoperative ( } 4 \text { days after } \\
\text { KPE/IOL) }\end{array}$ & PCIOL & Positive & CoNS & $\operatorname{IVAB}(I)$ & $\mathrm{CF}$ \\
\hline 12 & 67 & $M$ & $\begin{array}{l}\text { Postoperative ( } 75 \text { days } \\
\text { after KPRO surgery) }\end{array}$ & PCIOL & Positive & Streptococcus mitis & $\begin{array}{l}\text { IVAB }(2 / 2) \\
\text { PPV }\end{array}$ & HM \\
\hline 13 & 59 & $M$ & $\begin{array}{l}\text { Endogenous (unknown } \\
\text { source) }\end{array}$ & Phakia & Positive & $\begin{array}{l}\beta \text {-Hemolytic group } \\
C \text { Streptococcus }\end{array}$ & $\operatorname{IVAB}(I)$ & LP \\
\hline 14 & 12 & $\mathrm{~F}$ & Trauma & Phakia & Positive & Streptococcus mitis & IVAB (2/I2) PPV & LP \\
\hline 15 & 87 & $\mathrm{~F}$ & $\begin{array}{l}\text { Intravitreal injection } \\
\text { (ranibizumab) }\end{array}$ & PCIOL & Positive & Streptococcus mitis & $\operatorname{IVAB}(I)$ & HM \\
\hline 16 & 71 & $M$ & $\begin{array}{l}\text { Postoperative ( } 77 \text { days } \\
\text { after keratoplasty) }\end{array}$ & Aphakia & Positive & Fusarium & $\begin{array}{l}\text { IVAB (I) } \\
\text { PPV }\end{array}$ & LP \\
\hline
\end{tabular}

Notes: Lens status was at the time of endophthalmitis diagnosis. “*” means at the time of RD diagnosis.

Abbreviations: KPE/IOL, Kelman phacoemulsification and intraocular lens implantation; KPRO, keratoprosthesis; PCIOL, posterior chamber intraocular lens; CoNS, coagulase-negative staphylococci; MRSA, methicillin-resistant Staphylococcus aureus; IVAB, intravitreal antibiotics; PPV, pars plana vitrectomy; CF, counting fingers; LP, light perception; HM, hand motions; NLP, no light perception. 
(No. 4, 8, 11) after Kelman phacoemulsification and intraocular lens implantation (KPE/IOL). Three of these cases (No. 4, 12, 16) were defined as late-onset postoperative endophthalmitis, as their endophthalmitis occurred 44, 75, and 77 days after ocular surgery, respectively. Of the remaining seven exogenous endophthalmitis cases with subsequent RD, 2 (12.5\%) developed endophthalmitis after intravitreal injection, three developed endophthalmitis after open globe injury, and two others were secondary to corneal ulceration. In the four patients with endogenous endophthalmitis and subsequent $\mathrm{RD}$, the source of endogenous infection was attributed to MRSA bacteriemia from a presumed primary pulmonary focus (No.2), Streptococcus bacteremia from meningitis (No. 3), urinary tract infection with negative culture (No.9), and Streptococcus bacteremia from an unknown source (No. 13).

Potential risk factors related to $\mathrm{RD}$ after endophthalmitis were aphakia $(p=0.014)$ and the presence of posterior synechiae (PS) ( $p=0.023)$ (Table 3$)$. The presence of pseudophakia $(p=0.026)$ was higher in the endophthalmitis alone group. The median time to develop RD after endophthalmitis was 27 days (range: 1-581 days, IQR: 25.3). Thirteen (81.3\%) cases of RD occurred less than 2 months after the diagnosis of endophthalmitis. Two patients (No. 13, 16) developed RD between 2 and 4 months after endophthalmitis. Only one patient (No. 7) developed RD over 1 year from the time of endophthalmitis, and this patient had a complicated ocular history of KPRO and anterior scleritis with scleral thinning.

Eleven patients $(68.8 \%)$ in the RD cohort had positive ocular cultures, nine of which came from exogenous cases. Five cultures demonstrated less virulent pathogens with CoNS accounting for 4 cases (36.4\%) and Fusarium accounting for the other $(9.1 \%)$. The remaining six positive ocular cultures grew Streptococcus species $(\mathrm{N}=5$, $45.5 \%)$ and MRSA $(\mathrm{N}=1,9.1 \%)$.

Most of the patients $(\mathrm{N}=13,81.3 \%)$ were treated primarily with IVAB alone. One (7.7\%) patient received IVAB three times in 6 days, and four (30.8\%) other patients received antibiotic injections twice. Three (17.6\%) patients had PPV in addition to IVAB. Additionally, one patient (No. 8) received an intravitreal injection of dexamethasone $400 \mathrm{mcg} / 0.1 \mathrm{~mL}$.

Rhegmatogenous retinal detachment (RRD) was the most common type of $\mathrm{RD}(\mathrm{N}=8,50 \%)$ followed by tractional retinal detachment (TRD) $(\mathrm{N}=6,37.5 \%)$. One $(6.25 \%)$ patient had an exudative retinal detachment (ERD) and another patient (6.25\%) had a combined TRD/RRD. The macula was detached at the time of RD diagnosis in six eyes (38\%). Seven (43.8\%) patients had no surgical intervention for RD: one had an ERD and 6 patients opted to not undergo surgery. For those who underwent surgical repair for $\mathrm{RD}(\mathrm{N}=9,56.3 \%)$, eight

Table 3 Potential Factors Related to Occurrence of RD After Endophthalmitis

\begin{tabular}{|c|c|c|c|c|}
\hline \multirow[t]{3}{*}{ Potential Factor } & & \multicolumn{2}{|c|}{ RD Occurrence (\%) } & \multirow[t]{3}{*}{$P$ value } \\
\hline & & \multicolumn{2}{|c|}{ All Patients $(n=108)$} & \\
\hline & & $R D(n=16)$ & No RD ( $n=92)$ & \\
\hline \multirow[t]{3}{*}{ Phakic status (at the time of endophthalmitis) } & Pseudophakia & $5(31.3)$ & $58(63.0)$ & 0.026 \\
\hline & Aphakia & $3(18.8)$ & $2(2.2)$ & 0.023 \\
\hline & Phakia & $8(50.0)$ & $32(34.8)$ & 0.42 \\
\hline Posterior synechia & & $7(43.8)$ & $14(15.2)$ & 0.014 \\
\hline \multirow[t]{2}{*}{ Initial VA } & $\leq \mathrm{LP}$ & $7(43.7)$ & $23(25.0)$ & 0.14 \\
\hline & $>\mathrm{LP}$ & $9(56.3)$ & $69(75.0)$ & \\
\hline Hypopyon & & II (68.8) & $57(62.0)$ & 0.78 \\
\hline PVD & & $7(43.8)$ & $44(47.8)$ & 0.79 \\
\hline \multirow[t]{2}{*}{ Positive culture } & Virulent & $6(54.5)$ & $29(59.2)$ & $>0.99$ \\
\hline & Less virulent & $5(45.5)$ & $20(40.8)$ & \\
\hline PPV for endophthalmitis & & $3(18.8)$ & $24(26.1)$ & 0.76 \\
\hline
\end{tabular}

Notes: $P$ value was from Fisher's exact test. $P<0.05$ was considered statistically significant.

Abbreviations: APD, afferent pupillary defect; AMD, age-related macular degeneration; CD, choroidal detachment; ERM, epiretinal membrane; PVD, posterior vitreous detachment; PVR, proliferative vitreoretinopathy. 
Table 4 Treatment Strategies and Outcomes for RD After Endophthalmitis

\begin{tabular}{|c|c|c|c|c|c|c|c|c|}
\hline $\begin{array}{l}\text { Case } \\
\text { No. }\end{array}$ & $\begin{array}{l}\text { RD } \\
\text { Type }\end{array}$ & $\begin{array}{l}\text { Macula } \\
\text { Status }\end{array}$ & $\begin{array}{l}\text { Primary } \\
\text { Surgery }\end{array}$ & $\begin{array}{c}\text { Numbers of } \\
\text { Surgeries for RD }\end{array}$ & $\begin{array}{l}\text { Other Ocular Surgery } \\
\text { After RD Diagnosis }\end{array}$ & $\begin{array}{l}\text { Follow-Up } \\
\text { Time } \\
\text { (Months) }\end{array}$ & $\begin{array}{l}\text { Anatomic } \\
\text { Success } \\
(\mathbf{Y} / \mathbf{N})\end{array}$ & Final VA \\
\hline I & TRD & On & PPV & I & $\mathrm{CE} / \mathrm{IOL}$ & 13 & $\mathrm{~N}$ & Enucleation \\
\hline 2 & RRD & Off & PPV & I & $\begin{array}{c}\text { CE/IOL } \\
\text { YAG capsulotomy }\end{array}$ & 10 & $Y$ & $20 / 60$ \\
\hline 3 & $\begin{array}{l}\text { RRD/ } \\
\text { TRD }\end{array}$ & Off & PPV & 1 & Lysis of PS and PM & 9 & $Y$ & HM \\
\hline 4 & RRD & On & LR & 3 & None & 14 & $Y$ & $20 / 15$ \\
\hline 5 & RRD & On & $\mathrm{PPV}+\mathrm{SB}$ & I & $\begin{array}{l}\text { Intravitreal injection of } \\
\text { aflibercept }\end{array}$ & 63 & $Y$ & $20 / 60$ \\
\hline 6 & ERD & On & None & 0 & PKP and gluing & 20 & $Y$ & HM \\
\hline 7 & TRD & On & None & 0 & Lid surgery for ptosis & 20 & $\mathrm{~N}$ & $20 / 80$ \\
\hline 8 & RRD & Off & PPV & 2 & None & 54 & $Y$ & $20 / 25$ \\
\hline 9 & TRD & On & None & 0 & None & 9 & $N$ & Enucleation \\
\hline 10 & TRD & On & None & 0 & None & 16 & $\mathrm{~N}$ & Enucleation \\
\hline II & RRD & Off & PPV & I & None & 57 & $Y$ & HM \\
\hline 12 & TRD & Off & None & 0 & CTLC & 23 & $N$ & NLP \\
\hline 13 & RRD & On & PPV & I & $\begin{array}{c}\text { TKP/PKP/Pupillary } \\
\text { Membranecto-my/SO } \\
\text { removal }\end{array}$ & 42 & $Y$ & $20 / 40$ \\
\hline 14 & RRD & On & None & 0 & Lensectomy & 5 & $N$ & Evisceration \\
\hline 15 & RRD & On & PPV & I & $\begin{array}{l}\text { Intravitreal Injection of } \\
\text { Aflibercept DSAEK }\end{array}$ & 7 & $Y$ & LP \\
\hline 16 & TRD & Off & None & 0 & None & 1 & $\mathrm{~N}$ & Enucleation \\
\hline
\end{tabular}

Abbreviations: RRD, rhegmatogenous retinal detachment; TRD, tractional retinal detachment; ERD, exudative retinal detachment; PPV, pars plana vitrectomy; SO, silicon oil; LR, laser retinopexy; SB, scleral buckle; CE/IOL, cataract extraction with insertion of intraocular lens; YAG, yttrium-aluminum-garnet laser; PS, posterior synechiae; PM, pupillary membranes; CTLC, contact transscleral laser cyclophotocoagulation; PKP, penetrating keratoplasty; TKP, temporary keratoprosthesis; DSAEK, Descemet's stripping automated endothelium keratoplasty; HM, hand motion; CF, count fingers; LP, light perception; NLP, no light perception.

(88.9\%) underwent PPV alone and one (11.1\%) underwent PPV combined with a scleral buckle (SB). Two patients (No. 4, 8) required more than one surgery to achieve anatomic success, and one patient (No.1) who underwent repair did not achieve anatomic success and ultimately underwent enucleation. The rate of final retinal reapposition was 56.3\% (n=9/16) (Table 4).

The mean presenting VA at the time of RD diagnosis was 2.2 \pm 0.9 logMAR (range: 0.2-3; Snellen equivalent: 20/2891, [range: $20 / 150-\mathrm{NLP}$ ]; $\mathrm{N}=16$ ) with 14 patients (87.5\%) having a VA less than CF. The mean final VA was $1.3 \pm 1.2$ logMAR (range: -0.1 to 3 logMAR; Snellen equivalent: 20/418, [range: 20/15-NLP]; $N=11$ ) in patients with $R D$ after endophthalmitis (excluding the 5 patients who underwent enucleation or evisceration), with final VA of 20/400 or better in $6(54.5 \%)$ patients. After treatment for RD, hypotony (IOP $\leq 5 \mathrm{mmHg}$ ) developed in $3(18.8 \%$ ) patients, while 2 patients developed glaucoma or ocular hypertension. In addition, three (18.8\%) patients developed proliferative vitreoretinopathy (PVR) after RD diagnosis.

\section{Comparison of Outcomes in RD After Endophthalmitis $(n=16)$ versus Endophthalmitis Alone $(n=92)$}

Five patients $(31.3 \%)$ with RD after endophthalmitis eventually underwent enucleation or evisceration, compared to 
eight patients $(8.7 \%)$ with endophthalmitis alone $(\mathrm{p}=0.024)$ In the endophthalmitis alone cohort, VA was significantly improved after treatment compared to baseline, with mean initial and final VA of $1.9 \pm 0.8 \log$ MAR and $1.2 \pm 1.0 \log$ MAR $(p<0.0001)$, respectively. The mean initial and final VA of the $\mathrm{RD}$ cohort was $1.9 \pm 0.9 \log \mathrm{MAR}$ and $1.3 \pm 1.2 \log \mathrm{MAR}$ $(\mathrm{p}=0.07)$, respectively, demonstrating an improvement. There was no significant difference in the mean final VA for endophthalmitis patients with or without RD who did not undergo enucleation or evisceration $(p=0.73)$.

\section{Discussion}

Infectious endophthalmitis is a rare but serious ophthalmic emergency that may result in a poor visual outcome and permanent loss of vision. A major determinant for the prognosis of endophthalmitis is timely diagnosis that facilitates early intervention. ${ }^{16}$ However, despite early recognition of the infection and treatment with IVAB, the disease may progress and contribute to the formation of RD.

The most serious ocular sequala of endophthalmitis is the need to remove the eye or the intraocular contents. In this series, $8.7 \%$ of patients with endophthalmitis alone underwent enucleation or evisceration. However, in patients with $\mathrm{RD}$, this rate was a significantly higher at $31.3 \%$, confirming the inferior outcomes of patients who had RD secondary to endophthalmitis.

The incidence of RD after endophthalmitis was 14.8\% in this series, which is within the range reported in previous series in the literature $(8.3 \%-25 \%)$ over the past 35 years. $^{5-9}$ The possibility that patients might have predisposing factors before the diagnosis of RD was considered here. Aphakia was associated with RD formation in this study, which is consistent with previous literature. ${ }^{17-19}$ Patients with aphakia might have a higher risk of retinal tears and $\mathrm{RD}$, probably due to posterior capsular rupture and vitreous loss during lens removal. The rate of pseudophakia in the RD group was consistent with previous literature. ${ }^{20-22}$ Interestingly, the presence of pseudophakia was higher in the endophthalmitis alone group, with only $9.2 \%$ of the patients who had cataract surgery before endophthalmitis later developing an $\mathrm{RD}$. We do not suggest that pseudophakia was protective against the formation of RD. Rather the difference between our results and those of previous reports ${ }^{23-25}$ might be due to different characteristics of the study population.

Severity of intraocular inflammation at the time of endophthalmitis diagnosis likely contributes to the risk of developing RD. Interestingly, the presence of hypopyon or the virulence of the organism did not correlate with RD formation in this study. However, we interestingly find the presence of PS was significantly higher in the RD group as compared to the endophthalmitis alone group. The finding that PS but not hypopyon is associated with RD after endophthalmitis, in conjunction with the finding that some patients developed retinal detachment several months after completing antibacterial treatment, suggests that chronic inflammation persisting beyond the infectious window of endophthalmitis may be involved in the pathophysiology of late retinal detachment. ${ }^{26}$

Another potential contributor to the development of $\mathrm{RD}$ is the invasive nature of the intraocular procedures such as IVAB and PPV used for treating endophthalmitis. ${ }^{5}$ These procedures can cause iatrogenic retinal breaks that may precipitate or predispose patients to the development of RD. It has been suggested that a "jet stream" effect induced by intravitreal injection could create a retinal tear, especially in patients who have undergone vitrectomy. ${ }^{5}$ The "jet stream" effect happens when high velocity of fluid stream from the needle damages fragile retina with no vitreous cushion. However, the frequency of RD was $11.5 \%$ in patients who received both PPV and IVAB compared to $15.9 \%$ in the IVAB alone group in this study, which suggested this "jet stream" effect had minimal effect in this cohort of patients.

In the current study, the anatomic and functional outcomes for RD after endophthalmitis was poor. Nearly onethird patients required enucleation or evisceration. The final VA was $20 / 400$ or better in only $37.5 \%$ who did not undergo enucleation or evisceration. This was similar to the $39.7 \%$ observed by Dave et al. ${ }^{12}$ Initial and final mean $\mathrm{VA}$ in this series were $1.93 \pm 0.97 \log \mathrm{MAR}$ and $1.32 \pm 1.18$ $\log \mathrm{MAR}$, respectively, compared to $1.50 \pm 0.66 \log \mathrm{MAR}$ and $1.35 \pm 0.70 \log$ MAR in that study. The mean final VA in the two cohorts was similar, reflecting the generally poor functional outcomes of RD after endophthalmitis. The better initial VA in Dave et al may have resulted from the exclusion of inoperable eyes to evaluate silicone oil in RD repair, which usually had poor initial VA. Dave et al noted that the final reattachment was successful in $62.5 \%$ of cases, while either enucleation/evisceration or the final VA lower than CF occurred in $62.5 \%$ of cases. The fact that patients still had poor VA even with reattached retina, which was consistent with the Endophthalmitis Vitrectomy Study (EVS), ${ }^{8}$ demonstrated that the ocular damage to retinal cells caused by severe inflammation might be irreversible. 
A key limitation of our study was its retrospective nature. As a result, there were inherent differences in management protocol and baseline characteristics among subjects. The relative rarity of endophthalmitis and especially $\mathrm{RD}$ after endophthalmitis caused statistical analysis between many subgroups to be unfeasible or underpowered due to inadequate sample size within the groups. Additionally, the fact that this study is not restricted to the etiology of endophthalmitis or is limited only to select ophthalmic procedures or surgeries introduces a number of unmeasured variables that can not be reasonably quantified. Furthermore, the exclusion of patients with follow-up time less than 3 months after surgery for $\mathrm{RD}$ has the potential to lead to surveillance bias, as those with RD repair may have a longer observation period than some of those with endophthalmitis alone.

\section{Conclusion}

In summary, RD after endophthalmitis is often associated with poor anatomic and visual outcomes. Our data demonstrate that the presence of aphakia and posterior synechiae are associated with the development of RD after endophthalmitis. Enucleation or evisceration occurred in approximately one-third of cases of RD after endophthalmitis, highlighting the high rate of poor anatomic and functional outcome despite intervention.

\section{Disclosure}

The authors report no conflicts of interest for this work.

\section{References}

1. Novosad BD, Callegan MC. Severe bacterial endophthalmitis: towards improving clinical outcomes. Expert Rev Ophthalmol. 2010;5 (5):689-698. doi:10.1586/eop.10.52

2. Durand ML. Bacterial and Fungal Endophthalmitis. Clin Microbiol Rev. 2017;30(3):597-613. doi:10.1128/CMR.00113-16

3. López-Cabezas C, Muner DS, Massa MR, Mensa Pueyo JM. Antibiotics in endophthalmitis: microbiological and pharmacokinetic considerations. Curr Clin Pharmacol. 2010;5(1):47-54. doi:10.2174/ 157488410790410597

4. Clarke B, Williamson TH, Gini G, Gupta B. Management of bacterial postoperative endophthalmitis and the role of vitrectomy. Surv Ophthalmol. 2018;63(5):677-693. doi:10.1016/j.survophthal.2018.02. 003

5. Nelsen PT, Marcus DA, Bovino JA. Retinal detachment following endophthalmitis. Ophthalmology. 1985;92(8):1112-1117. doi:10.101 6/s0161-6420(85)33916-7

6. Chiquet C, Aptel F, Combey-de Lambert A, et al. Occurrence and risk factors for retinal detachment after pars plana vitrectomy in acute postcataract bacterial endophthalmitis. Br J Ophthalmol. 2016;100 (10):1388-1392. doi:10.1136/bjophthalmol-2015-307359

7. Lee CS, Khan M, Patrie J, Bajwa A, Shildkrot YE. Pars plana vitrectomy for endophthalmitis: microbiologic spectrum and clinical outcomes. Ocul Immunol Inflamm. 2020;1-6. doi:10.1080/092739 48.2019.1698750
8. Doft BM, Kelsey SF, Wisniewski SR. Retinal detachment in the endophthalmitis vitrectomy study. Arch Ophthalmol. 2000;118 (12):1661-1665. doi:10.1001/archopht.118.12.1661

9. Feng HL, Robbins CB, Fekrat S. A nine-year analysis of practice patterns, microbiologic yield, and clinical outcomes in cases of presumed infectious endophthalmitis. Ophthalmol Retina. 2020;4 (6):555-559. doi:10.1016/j.oret.2020.03.009

10. Kimura D, Sato T, Suzuki H, et al. A case of rhegmatogenous retinal detachment at late stage following endogenous bacterial endophthalmitis. Case Rep Ophthalmol. 2017;8(2):334-340. doi:10. $1159 / 000477160$

11. Foster RE, Rubsamen PE, Joondeph BC, Flynn HW, Smiddy WS. Concurrent endophthalmitis and retinal detachment. Ophthalmology. 1994;101(3):490-498. doi:10.1016/s0161-6420 (94)31308-x

12. Dave VP, Pathengay A, Relhan N, et al. Endophthalmitis and concurrent or delayed-onset rhegmatogenous retinal detachment managed with pars plana vitrectomy, intravitreal antibiotics, and silicone oil. Ophthalmic Surg Lasers Imaging Retina. 2017;48(7):546-551. doi:10.3928/23258160-20170630-05

13. Cornut PL, Thuret G, Creuzot-Garcher C. Relationship between baseline clinical data and microbiologic spectrum in 100 patients with acute postcataract endophthalmitis. Retina. 2012;32(3):549-557. doi:10.1097/IAE.0b013e3182205996

14. Baughman DM, Su GL, Tsui I, Lee CS, Lee AY. Validation of the Total Visual Acuity Extraction Algorithm (TOVA) for automated extraction of visual acuity data from free text, unstructured clinical records. Transl Vis Sci Technol. 2017;6(2):2. doi:10.1167/ tvst.6.2.2

15. Lange C, Feltgen N, Junker B, Schulze-Bonsel K, Bach M. Resolving the clinical acuity categories "hand motion" and "counting fingers" using the Freiburg Visual Acuity Test (FrACT). Graefes Arch Clin Exp Ophthalmol. 2009;247(1):137-142. doi:10.1007/s00417-0080926-0

16. Ching Wen Ho D, Agarwal A, Lee CS, et al. A review of the role of intravitreal corticosteroids as an adjuvant to antibiotics in infectious endophthalmitis. Ocul Immunol Inflamm. 2018;26(3):461-468. doi:10.1080/09273948.2016.1245758

17. Byer NE. Natural history of posterior vitreous detachment with early management as the premier line of defense against retinal detachment. Ophthalmology. 1994;101(9):1503-1513. doi:10.1016/ s0161-6420(94)31141-9

18. Bhardwaj G, Walker RJE, Ezra E, Mirza Z, Muqit MMK. A 21-year study of vitreoretinal surgery for aphakic retinal detachment: long-term surgical outcomes and complications. Ophthalmol Retina. 2019;3(9):784-790. doi:10.1016/j.oret.2019. 04.002

19. Petousis V, Sallam AA, Haynes RJ, et al. Risk factors for retinal detachment following cataract surgery: the impact of posterior capsular rupture. Br J Ophthalmol. 2016;100(11):1461-1465. doi:10.11 36/bjophthalmol-2015-307729

20. Ramos M, Kruger EF, Lashkari K. Biostatistical analysis of pseudophakic and aphakic retinal detachments. Semin Ophthalmol. 2002;17 (3-4):206-213. doi:10.1076/soph.17.3.206.14784

21. Russell M, Gaskin B, Russell D, Polkinghorne PJ. Pseudophakic retinal detachment after phacoemulsification cataract surgery: ten-year retrospective review. J Cataract Refract Surg. 2006;32 (3):442-445. doi:10.1016/j.jcrs.2005.12.095

22. Karczewicz D, Lubiński W, Podboraczyńska-Jodko K, Spoz E. Odwarstwienie siatkówki w oczach po operacji zaćmy metoda fakoemulsyfikacji [Pseudophakic retinal detachment after cataract surgery by phacoemulsification]. Ann Acad Med Stetin. 2006;52 (2):79-82.

23. Haug SJ, Bhisitkul RB. Risk factors for retinal detachment following cataract surgery. Curr Opin Ophthalmol. 2012;23(1):7-11. doi:10.10 97/ICU.0b013e32834cd653 
24. Coppé AM, Lapucci G. Posterior vitreous detachment and retinal detachment following cataract extraction. Curr Opin Ophthalmol. 2008;19(3):239-242. doi:10.1097/ICU.0b013e3282fc9c4a

25. Qureshi MH, Steel D. Retinal detachment following cataract phacoemulsification-a review of the literature. Eye. 2020;34 (4):616-631. doi:10.1038/s41433-019-0575-z
26. Kunavisarut P, Srisomboon T, Patikulsila D, et al. Risk factors for development of rhegmatogenous retinal detachment in patients with uveitis. Ocul Immunol Inflamm. 2019;27(4):681-685. doi:10.1080/ 09273948.2018 .1424343

\section{Publish your work in this journal}

Clinical Ophthalmology is an international, peer-reviewed journal covering all subspecialties within ophthalmology. Key topics include: Optometry; Visual science; Pharmacology and drug therapy in eye diseases; Basic Sciences; Primary and Secondary eye care; Patient Safety and Quality of Care Improvements. This journal is indexed on PubMed

Submit your manuscript here: https://www.dovepress.com/clinical-ophthalmology-journal
Central and CAS, and is the official journal of The Society of Clinical Ophthalmology (SCO). The manuscript management system is completely online and includes a very quick and fair peer-review system, which is all easy to use. Visit http://www.dovepress.com/ testimonials.php to read real quotes from published authors. 